\title{
Community Diagnosis dan Peningkatan Pengetahuan Penyakit Hipertensi pada Masyarakat RT. 02 Desa Dalam, Kecamatan Alas, Sumbawa
}

\author{
Dian Oktamulada Utami ${ }^{1}$, Sulistyawati ${ }^{2}$ \\ 1,2 Fakultas Kesehatan Masyarakat, Universitas Ahmad Dahlan \\ E-mail: 'dian1800029219@webmail.uad.ac.id, ${ }^{2}$ sulistyawati.suyanto@uad.ac.id
}

\begin{abstract}
Abstrak
Tidak semua wilayah di Indonesia memiliki pemetaan masalah kesehatan di lingkup wilayahnya. Padahal hal itu penting untuk menentukan prioritas masalah yang harus ditangani. Community diagnosis merupakan teknik untuk menjaring masalah utamanya kesehatan. Hipertensi merupakan masalah yang umum dijumpai pada masyarakat Indonesia, bahkan cenderung diabaikan karena proses perkembangan penyakit yang tidak terlihat secara nyata. Tujuan pengabdian masyarakat ini adalah melakukan community diagnosis untuk melihat masalah prioritas di lokasi untuk selanjutnya dilakukan intervensi kepada masyarakat. Ditemukan bahwa hipertensi menjadi masalah utama. Peningkatan pengetahuan hipertensi dilakukan dengan pemasangan media edukasi berupa poster.
\end{abstract}

Kata kunci: Community Diagnosis, Hipertensi, Peningkatan Pengetahuan, Edukasi

\section{Abstract}

Community diagnosis is a technique to capture the main health problems. Hypertension is a common problem in Indonesian society and is even ignored because the disease development process is not visible. This community service aims to carry out a community diagnosis to see priority problems in the location for further intervention to the community. It was found that hypertension was the main problem. Increasing knowledge of the society about hypertension is conducted by installing posters in the public space.

Keywords: Community Diagnosis, Hypertention, Knowledge Enhancement, Education

\section{PENDAHULUAN}

Community diagnosis atau diagnosis komunitas merupakan upaya sistematis yang meliputi pemecahan masalah kesehatan keluarga sebagai unit primer komunitas masyarakat yang menjadi fokus penegakkan diagnosis komunitas. Tujuan dari community diagnosis adalah untuk mengidentifikasi dan menganalisis permasalahan kesehatan yang mendasar, menemukan prioritas masalah dan menyusun solusi hingga alternatif pemecahan masalah [1]. Dengan menggunakan pendekatan ini, masalah yang ada di masyarakat dapat diidentifikasi secara bertahap [2].

Menurut Nur Furqani dkk (2020), Hipertensi adalah suatu keadaan dimana tekanan darah dalam tubuh yang tinggi dan bersifat abnormal, memiliki angka sistolik dan diastolik yang lebih tinggi dari 140/90mmHg [3]. Keadaan tekanan darah yang meningkat dalam durasi yang lama bisa menyebabkan rusaknya pembuluh darah pada organ tubuh seperti ginjal, jantung, otak dan mata. Badan kesehatan dunia (WHO) memperkirakan hingga tahun 2019 angka kejadian hipertensi secara global sebesar $22 \%$ total penduduk dunia. Dari jumlah tersebut, kurang dari setengahnya yang telah 
berupaya mengendalikan tekanan darahnya [4]. Hipertensi merupakan salah satu penyakit yang menyebabkan tingkat kematian tertinggi di dunia atau sering disebut dengan silent killer. Penyakit ini mengakibatkan berbagai komplikasi yang dapat menyerang berbagai organ antara lain kardiovaskular, hipertensi ensefalopati, penyakit hipertensi serebrovaskular, dan hipertensi retinopati [5].

Menurut Riskesdas tahun 2018, angka penderita hipertensi di Indonesia cukup tinggi, mencapai lebih dari 63 juta jiwa, dengan prevalensi kematian lebih dari 400 ribu jiwa [6]. Banyak hal yang dapat menjadi pemicu hipertensi: diet tidak sehat, over kalori, aktivitas fisik yang rendah, serta kegemukan. Ketika aktivitas fisik kurang, maka akan terjadi peningkatan denyut jantung yang mana dapat menjadi beban bagi jantung untuk memompa darah lebih kuat dan menimbulkan peningkatan tekanan darah [7]. Berdasarkan data Profil Kesehatan dari Puskesmas Alas tahun 2019, disebutkan bahwa hipertensi merupakan penyakit tertinggi ketiga di Kecamatan Alas setelah ISPA dan penyakit kulit yaitu mencapai 437 orang dari total sebanyak 29.405 orang penduduk pada tahun 2019. Sedangkan untuk data di Desa Dalam, selama setahun jumlah penduduk yang melakukan pengukuran tekanan darah sebanyak 194 orang dan yang mengalami tekanan darah tinggi adalah sebanyak 64 orang dari total 2.750 orang penduduk $>18$ tahun pada tahun 2019.

Rendahnya pengetahuan terkait masalah hipertensi bagi masyarakat khususnya lansia mempengaruhi persepsi mereka dalam menanggapi permasalahan hipertensi yang sedang diderita. Persepsi yang terkadang kurang tepat saat menghadapi penyakit hipertensi pada lansia dapat berdampak pada saat penerapan perawatan lansia dengan penyakit hipertensi. Sehingga sangat diperlukan adanya edukasi kesehatan guna meningkatkan pengetahuan masyarakat khususnya lansia [8]. Pemberian edukasi kesehatan penyakit hipertensi kepada masyarakat di RT. 02 Desa Dalam, Kecamatan Alas, Kabupaten Sumbawa merupakan tindak lanjut dari community diagnosis yang dilaksanakan sebagai satu kesatuan rangkaian pencegahan penyakit. Pelaksanaan Community diagnosis dilakukan kepada $32 \mathrm{KK}$ dengan mewawancarai kepala keluarga atau perwakilannya yang bersedia. Sedangkan untuk pelaksanaan edukasi kesehatan penyakit hipertensi dilakukan kepada masyarakat khususnya penderita hipertensi di posyandu lansia di RT 02 Desa Dalam, Kecamatan Alas.

Media edukasi poster dipercaya merupakan media yang efektif dan efisien dalam mengirimkan pesan pada suatu intervensi. Bentuknya yang dapat berwarna warni dan gambar dapat menarik perhatian bagi pembacanya. Dengan melihat kebutuhan mitra baik dari data maupun hasil Community diagnosis maka pengabdian masyarakat ini memfokuskan pada peningkatan pengetahuan masyarakat tentang hipertensi melalui media poster.

\section{METODE}

Rangkaian pengabdian masyarakat ini dilaksanakan melalui dua tahap untuk mengetahui permasalahan mitra: 1) community diagnosis, 2) peningkatan pengetahuan melalui pemasangan poster tentang hipertensi. Peningkatan pengetahuan hipertensi dengan memberikan pengetahuan tentang gejala dan pencegahan hipertensi melalui pemasangan poster. Metode ini dipilih karena saat pelaksanaan masih situasi pandemic COVID-19 sehingga oleh otoritas setempat disarankann tidak kontak langsung dengan lansia. 
Pemasangan poster edukasi kesehatan dilakukan di papan pengumuman Posyandu Lansia Desa Dalam pada tanggal 15 Mei 2021. Diharapkan dengan metode ini sasaran edukasi bisa lebih luas yaitu menjangkau seluruh masyarakat RT. 02 Desa Dalam, khususnya lansia dan penderita hipertensi.

\section{HASIL DAN PEMBAHASAN}

Kegiatan pengabdian ini berjalan dengan baik dengan segala keterbatasan selama pandemic COVID-19 ini. Kegiatan dimulai dengan community diagnosis status kesehatan masyarakat dengan pengisian kuisioner. Setelah melakukan analisis, pengabdian berlanjut dengan melakukan kegiatan intervensi kepada masyarakat dengan pemasangan poster edukasi kesehatan yang bertempat di papan pengumuman Posyandu Lansia Desa Dalam. Pelaksanaan intervensi ini sebelumnya telah melewati tahap analisis dan identifikasi masalah yang diperoleh dari hasil community diagnosis sebelumnya. Terdapat 3 pokok permasalahan kesehatan yang disepakati yaitu:

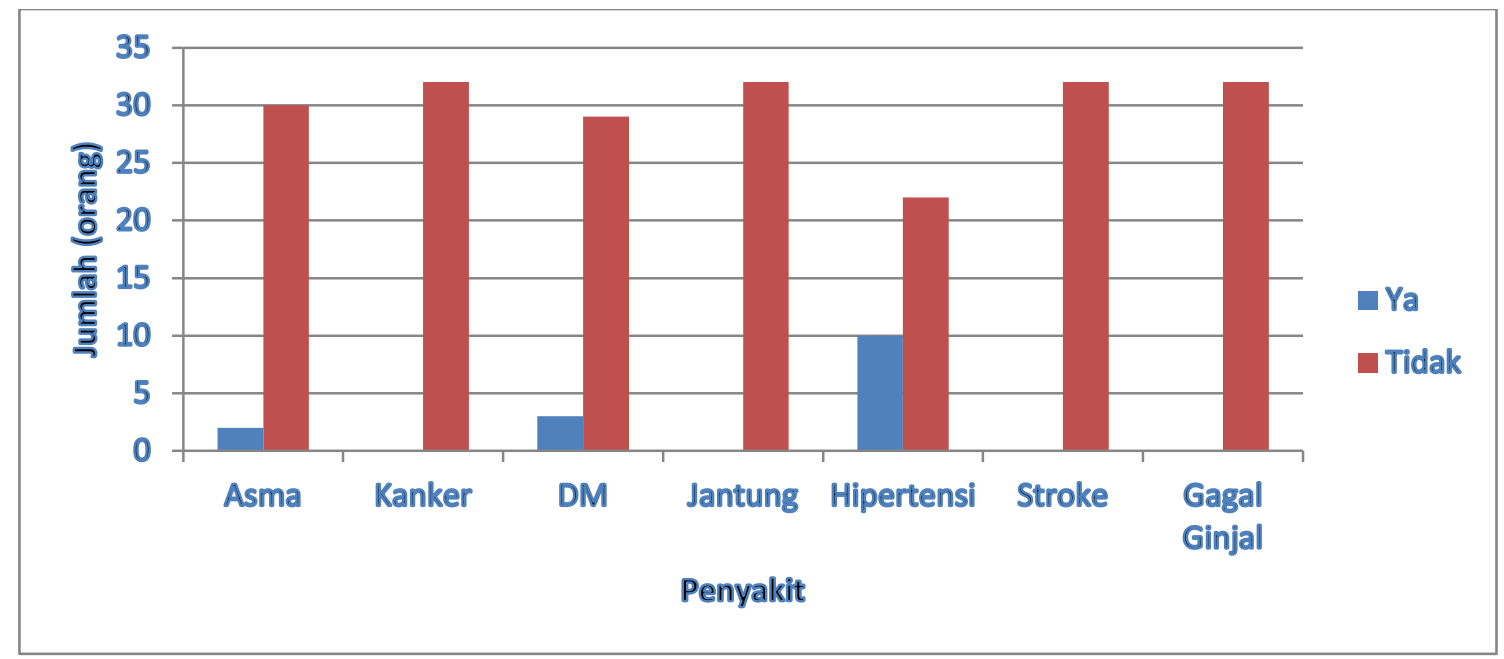

Gambar 1. Prevalensi Penyakit Tidak Menular di Desa Alam, Kecamatan Alas, Sumbawa

Berdasarkan Gambar 1, diketahui hasil paling tinggi yaitu pada penyakit Hipertensi dengan jumlah sebesar 10 orang yang mengalami hipertensi, kemudian disusul penyakit Diabetes Melitus dengan jumlah 3 orang, dan terakhir penyakit Asma dengan jumlah 2 orang.

Selanjutnya bersama mitra disepakati bahwa prioritas masalah yang disepakati untuk diselesaikan adalah hipertensi dengan melakukan upaya peningkatan pengetahuan kepada masyarakat melalui pemasangan poster edukasi. Poster dipilih karena menjadi media edukasi yang efektif dan terbukti nyata meningkatkan pengetahuan pembacanya secara signifikan [9], [10]. 


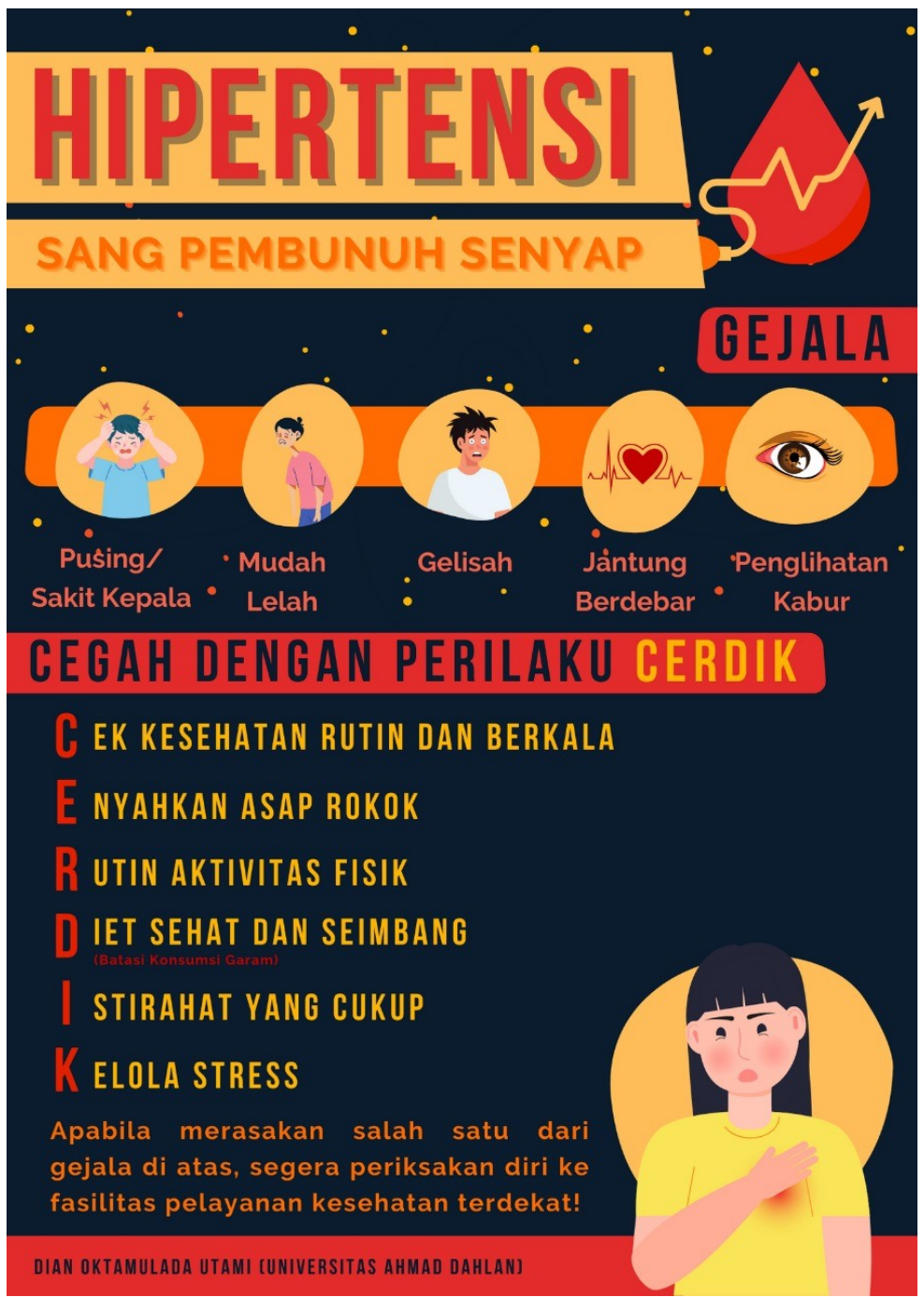

Gambar 2. Poster Edukasi Kesehatan di Posyandu Lansia Desa Dalam, Kecamatan Alas, Sumbawa

Dengan memberikan edukasi kepada masyarakat, dampak yang diharapkan dapat mengatasi permasalahan penyakit hipertensi di lokasi tersebut. Lebih jauh diharapkan dapat mendorong masyarakat untuk mengubah kebiasaan kearah pola hidup sehat yang lebih baik dan juga mencegah hipertensi sejak dini [11]. Peningkatan pengetahuan terkait penyakit hipertensi diharapkan berdampak pada menurunnya angka kejadian penyakit hipertensi ditengah masyarakat sehingga derajat kesehatan masyarakat dapat meningkat [12].

Pengukuran dampak dari pengabdian dilakukan secara langsung namun hanya kepada kader posyandu lansia, hal ini karena batasan kontak dengan anggota posyandu. Para kader menyebutkan bahwa pemasangan poster edukasi seperti dalam kegiatan penting untuk memberikan pengetahuan dan informasi kepada masyarakat. Hal ini karena selama ini, poster edukasi jarang terpasang di lokasi. Di lokasi, satu-satunya poster yang terpasang hanyalah poster tentang COVID-19.

Selain itu para kader menyebutkan harapan besar mereka bahwa poster yang terpasang agar bisa dibaca oleh para wali lansia (anggota keluarga yang mengantar 
lansia) ke posyandu. Sehingga para wali tersebut dapat berperan dalam pengawasan pola hidup lansia saat dirumah masing-masing. Hal ini sesuai dengan hasil temuan beberapa penelitian yang menyebutkan bahwa dukungan keluarga memegang peranan penting dalam manajemen penyakit hipertensi di masyarakat [10], [13].

Secara umum tidak terdapat kendala berarti dalam proses pelaksanaan pengabdian kepada masyarakat ini. Namun demikian, karena adanya situasi pandemic, maka proses edukasi yang direncanakan tidak bisa dilaksanakan secara langsung kepada masyarakat namun diganti melalui media poster.

\section{KESIMPULAN DAN SARAN}

Pengabdian masyarakat ini dilaksanakan melalui dua tahap yaitu community diagnosis dan upaya peningkatan pengetahuan kepada masyarakat. Masyarakat berpartisipasi aktif dalam pelaksanaan community diagnosis namun untuk pelaksanaan intervensi peningkatan pengetahuan tidak dapat dilaksanakan secara langsung karena situasi pandemi ini, sehingga dilakukan dengan menggunakan poster dan dipasang ditempat umum. Para pengurus lansia mengemukakan bahwa pembuatan media edukasi serupa penting dilakukan dan diharapkan dapat dilakukan secara terus menerus untuk memperbarui pengetahuan masyarakat.

Berdasarkan pada fakta yang ditemui dilapangan, dapat disarankan kepada para pihak terkait agar melakukan upaya lebih aktif dalam memberikan edukasi kepada masyarakat, utamanya menggunakan media-media yang menarik sebagai pengganti aktifitas promosi kesehatan yang biasanya dilakukan secara tatap muka. Sedangkan kepada masyarakat, disarankan perlunya kesadaran untuk merubah perilaku sehat seperti berolahraga, diet sehat dan mengurangi stress untuk mencegah hipertensi.

\section{UCAPAN TERIMA KASIH}

Kami mengucapkan terimakasih kepada Program Studi Kesehatan Masyarakat - UAD, yang telah memfasilitasi kegiatan pengabdian kepada masyarakat ini. Kepada masyarakat dan pemerintah Desa Dalam - Kecamatan Alas dan Puskesmas Alas yang telah memberikan dukungan baik moril maupun data.

\section{DAFTAR PUSTAKA}

[1] V. Hadju, "Prosiding Kongres Nasional Ikatan Ahli Kesehatan Masyarakat ke-13 ( KONAS IAKMI XIII ) ' Masyarakat Hidup Sehat dan Bahagia dalam Mencapai Sasaran Pembangunan Berkelanjutan ( SDGs 2030 )' Edisi Kedua,” Pros. KONAS IAKMI XIII, vol. 2, no. November 2016, 2016.

[2] D. Katiandagho, Darwel, and E. I. Kulas, "Diagnosis Komunitas di Kelurahan Pogangan Kecamatan Gunungpati Kota Semarang Tahun 2011," J. Kesehat. Lingkung., vol. 2, no. 1, pp. 139-147, 2012.

[3] B. Nuraini, "Risk Factors of Hypertension," J Major., vol. 4, no. 5, pp. 10-19, 2015.

[4] N. Furqani, C. Rahmawati, and M. Melianti, "Hubungan Gaya Hidup Dengan Kejadian Hipertensi Pada Pasien Rawat Jalan di Puskesmas Pagesangan Periode Juli 2019," Lumbung Farm. J. Ilmu Kefarmasian, 2020, doi: 10.31764/lf.v1i1.1635.

[5] A. Sylvestris, "Hipertensi Dan Retinopati Hipertensi," Saintika Med., vol. 10, no. 1, p. 1, 2017, doi: 10.22219/sm.v10i1.4142.

[6] Kementerian Kesehatan Republik Indonesia Direktorat Pencegahan dan Pengendalian Penyakit Tidak Menular, "Hari Hipertensi Dunia 2019: 'Know Your Number, Kendalikan Tekanan Darahmu dengan CERDIK.' - Direktorat P2PTM," Web Page, 2019. http://p2ptm.kemkes.go.id/kegiatan-p2ptm/pusat-/hari-hipertensi-dunia-2019- 
know-your-number-kendalikan-tekanan-darahmu-dengan-cerdik (accessed Jun. 27, 2021).

[7] Y. E. Michael Sihotang, "Hubungan aktivitas fisik dengan tekanan darah pada lansia hipertensi," CHMK Nurs. Sci. J., vol. 4, no. April, pp. 1-10, 2020.

[8] L. L. Lolo and S. Sumiati, "Dampak Edukasi Hipertensi Berbasis Budaya Luwu Terhadap Pengetahuan Penderita Hipertensi," Voice of Midwifery, vol. 9, no. 1, pp. 823832, 2019, doi: 10.35906/vom.v9i1.82.

[9] D. L. Caesar and B. A. Prasetya, "Efektifitas Media Poster Dalam Meningkatkan Pengetahuan Sanitasi Dasar Di Sdn 01 Wonosoco Undaan Kudus," J-KESMAS J. Kesehat. Masy., vol. 6, no. 1, p. 83, 2020, doi: 10.35329/jkesmas.v6i1.655.

[10] H. Efendi and T. Larasati, "Dukungan Keluarga dalamManajemen Penyakit Hipertensi Family Support in Hypertension Disease 's Management," Majority, vol. 6, pp. 34-40, 2017.

[11] H. Setiawan, S. Suhanda, E. Rosliati, A. Firmansyah, and A. Fitriani, "Promosi Kesehatan Pencegahan Hipertensi Sejak Dini," ABDIMAS J. Pengabdi. Masy., vol. 1, no. 2, pp. 41-45, 2018, doi: 10.35568/abdimas.v1i2.328.

[12] E. K. R. Sudarsono, J. F. A. Sasmita, A. B. Handyasto, N. Kuswantiningsih, and S. S. Arissaputra, "Peningkatan Pengetahuan Terkait Hipertensi Guna Perbaikan Tekanan Darah pada Pemuda di Dusun Japanan, Margodadi, Seyegan, Sleman, Yogyakarta," J. Pengabdi. Kpd. Masy. (Indonesian J. Community Engag., vol. 3, no. 1, p. 26, 2017, doi: 10.22146/jpkm.25944.

[13] Y. A. Novitasari and N. Nirmalasari, "Studi Deskriptif: Sikap, Pengawasan Keluarga, Tingkat Pengetahuan dan Upaya Pengendalian Hipertensi Pada Lansia," J. Keperawatan Glob., vol. 5, no. 2, pp. 110-116, 2020, doi: 10.37341/jkg.v5i2.120. 